\title{
Daily living activities among geriatric residents at geriatric homes in Erbil and Sulaimaniyah cities, Kurdistan Region
}

\begin{tabular}{ccc}
\hline Sideeq Sadir Ali * & Jawdat Mamand Alhagbaker $* *$ & Nazar P. Shabila $* * *$ \\
\hline Abstract &
\end{tabular}

Background and objective: Maintaining the ability to perform basic self-care activities by the older adults is fundamental to maintaining their independence and quality of life. This study aimed to assess the level of functional dependency of the residents of geriatric homes in Erbil and Sulaymaniyah cities.

Methods: This cross-sectional study involved 94 older adults living in geriatric homes in Erbil and Sulaymaniyah cities. Data was collected on the socio-demographic characteristics, clinical characteristics, social issues and daily recreation activities of the participants using a questionnaire. Nine essential activities of daily living were assessed through a three-point Likert scale of independent, requires assistance and dependent.

Results: The mean and standard deviation age of the participants was $71.88 \pm 8.94$ years (range $60-81$ years). Around half $(43.6 \%)$ of the participants had at least one dependent activity. The level of dependency was highest in shopping, climbing stairs and bathing activities. Dependency of activities of daily living was significantly $(P<0.001)$ higher in females than males; in illiterate and those read and write than primary school graduates and secondary school and higher level graduates; in those self-employed before entering geriatric home than retired and unemployed; and in ex-smokers and non-smokers than smokers.

Conclusion: The level of independency in the different daily living activities was relatively high, which might be attributed to having a younger age group of elderly in the geriatric homes. Dependency was significantly associated with the sex, education level, employment status and smoking status of the participants.

Keywords: Activities; Daily living; Geriatric; Dependency; Independency; Kurdistan.

\section{Introduction}

Activities of daily living (ADL) refer to the daily activities of self-care at the place of residence of an individual, the outdoor surroundings, or both. Health professionals refer to the ability or the inability to perform the $A D L$ as an important measurement of the function status of an individual, especially concerning the people with disabilities and the elderly. ${ }^{1}$ A principle goal of the care of older patients is maintaining the ability to perform essential self-care activities such as bathing, dressing, using a toilet, transferring out of a bed or chair, and eating without assistance. These activities are fundamental to maintaining older people's independence, and quality of life. ${ }^{2}$ In older people, cognitive state, and ADL functioning are important for mortality, institutionalization, and quality of life. ${ }^{3}$ Aging is a natural phenomenon involving a socio-biological process. Aging can be usual aging that includes changes due to the aging process in addition to the effects of diseases, environmental and unhealthy lifestyle factors. It can also be successful aging, which refers to the aging process unaffected by diseases, environmental factors or lifestyle. ${ }^{4}$ The population of the world is aging so rapidly that the proportion of the world's population more than 60 years old is estimated to double from

* Department of Adult Nursing, College of Nursing, Hawler Medical University, Erbil, Iraq.

** Department of Community Nursing, College of Nursing, Hawler Medical University, Erbil, Iraq.

*** Department of Community Medicine, College of Medicine, Hawler Medical University, Erbil, Iraq. 
approximately $11 \%$ to $22 \%$ by 2050 . The absolute number of all people aged 60 years or more is expected to increase to two billion by that time. ${ }^{1}$ The United Nations Educational, Scientific, and Cultural Organization (UNESCO) revealed that the total population of Iraq was $24,246,000$ in 2002 and the percentage of the age group 65 years and over was $3 \% .^{5}$ A study conducted in 2013 on geriatric residents in Erbil geriatric home showed that the majority $(71.4 \%)$ of these residents were within the age group $61-80$ years old. ${ }^{6}$ Another study conducted in 2012 on geriatric residents in Sulaymaniyah geriatric home showed that $69.2 \%$ of the sample were within the age group 60-79 years. ${ }^{7}$ Currently, the geriatrics health services are poorly integrated into the health system in Kurdistan region. Up to the authors' knowledge, there are no published studies in the region regarding the independency of ADL in geriatric homes. Therefore, this study can help in improving the care and screening for undetected problem among geriatrics population. This study aimed to assess the $A D L$ in residents of geriatric homes in Kurdistan region and to find out the association between dependent activities with socio-demographic, medical and social characteristics.

\section{Methods}

This cross-sectional study was carried out in the only two geriatric homes that are available in Iraqi Kurdistan Region. There is a geriatric home in Erbil city accommodating 53 geriatric persons and another one in Sulaymaniyah city providing residence to 41 geriatric individuals while there is no geriatric home in Duhok or Halabja cities. The study was carried out from July $1^{\text {st }}, 2015$ to March $1^{\text {st }}, 2016$. All the 94 residents living in the two geriatric homes in Erbil and Sulaymaniyah cities were included in the study. However, six residents were excluded; two from Erbil and four from Sulaymaniyah as they were outside the geriatric homes on the days of the survey. A questionnaire consisting of four parts was developed to collect data from the participants. Development of parts one to three was based on a review of relevant literature, while part four included a validated standard tool to assess ADL. Part one included six questions about the socio-demographic characteristics of the study participants; governorate of residence, age, sex, educational level, occupation and marital status before entry to the geriatric home. Part two included four questions about medical and surgical history and smoking pattern of the participants. Part three consisted of eight questions about social issues and daily recreation activity; going out from geriatric home to visit families and relatives, having visitors to the geriatric home, watching television, listening to radio, reading newspapers or books, using a computer and doing any religious spirituals with the type of religious spirituals. Part four included a standard tool to assess the ADL that included nine essential activities of feeding, oral care, toileting, bathing, dressing, grooming, physical ambulation, climbing stairs and shopping. ${ }^{8}$ The questionnaire was pre-tested on a sample of 10 geriatric residents in geriatric homes before finalizing it and using it in this study. Data was collected from October $15^{\text {th }}$ to November $4^{\text {th }}, 2015$. Data was collected by direct interview with the participants. Interviewing each person took around 15 to 20 minutes to complete the response for all parts of the questionnaire. The participants were asked to rate each of the nine ADL on a three-point Likert scale of independent $(=0)$, requires assistance $(=1)$ and dependent (= 2). Independent for each activity means the person can perform the activity with no supervision, direction or personal assistance. Require assistance for each activity means that the individual needs some help to carry out the activity such as needing help to tying shoes for dressing activity or needing help to bathing a single part of the body for bathing activity. Dependent for each 
activity means the person cannot perform the activity without supervision, direction, personal assistance or total care. Verbal consent was taken from each individual before participation the study. The study was approved by the Research Ethics Committee of the College of Nursing at Hawler Medical University. Institutional permission was obtained from the Directorate of Social Care in Erbil and Sulaymaniyah and the geriatrics homes to gain access and get cooperation during this study. Data was analyzed by the statistical package for the social sciences (version 20). Descriptive statistics included calculating frequencies and percentages. For inferential statistics, the participants were categorized into those having at least one dependent ADL and those having no any dependent ADL. Association between dependency of ADL with the different socio-demographic, social and medical characteristics of the participants was assessed using Chi-Square test. A $P$ value of $\leq 0.05$ was considered statistically significant.

\section{Results}

Of the 94 participants, $56.4 \%$ were living in the Geriatric Home in Erbil city, and $43.6 \%$ were residing in the Geriatric Home in Sulaymaniyah city. The mean ( \pm SD) age of the participants was $71.88 \pm 8.94$ years (range 60-81 years). More than half $(52.1 \%)$ of the participants were between 60 and 70 years old. Most of the participants were male $(76.6 \%)$ and illiterate $(62.8 \%)$. Before entering to the geriatric home, most participants were selfemployed (57.4\%) and married (60.6\%). Table 1 shows the socio-demographic characteristics of the study participants.

Table 1: Socio-demographic characteristics of geriatric residents.

\begin{tabular}{llcc}
\hline \multirow{2}{*}{ Characteristics } & & No.=94 & (\%) \\
\hline Governorate & Erbil & 53 & $(56.4)$ \\
& Sulaymaniyah & 41 & $(43.6)$ \\
Age group (years) & $60-70$ & 49 & $(52.1)$ \\
& $71-80$ & 29 & $(30.9)$ \\
Sex & $\geq 81$ & 16 & $(17)$ \\
\multirow{4}{*}{ Education level } & Male & 72 & $(76.6)$ \\
& Female & 22 & $(23.4)$ \\
& Illiterate & 59 & $(62.8)$ \\
& Can read and write & 7 & $(7.4)$ \\
& Primary school & 14 & $(14.9)$ \\
Occupation before entering to & Secondary school & 9 & $(9.6)$ \\
the geriatric home & Higher Education graduate & 5 & $(5.3)$ \\
& Unemployment & 13 & $(13.8)$ \\
& Retired & 22 & $(23.4)$ \\
Marital status before entering & Self-employed & 54 & $(57.4)$ \\
the geriatric home & Governmental employed & 5 & $(5.3)$ \\
& Single & 36 & $(38.3)$ \\
& Married & 57 & $(60.6)$ \\
& Divorced & 1 & $(1.1)$ \\
\hline
\end{tabular}


Thirty-one $(33 \%)$ participants were relatives, and friends. Around half $(48.9 \%)$ smokers, and $10 \quad(10.6 \%)$ were of the participants had family, relatives and ex-smokers. More than half $(58.5 \%)$ of friends visiting them at the geriatric home. participants had chronic diseases, and Regarding daily recreation activity; the $19.1 \%$ of them had hypertension majority $(60.6 \%)$ of participants watched (Table 2). Nearly half $(48.9 \%)$ of the study participants used to go out from the geriatric home to visit their families, television, followed by listening the radio $(48.9 \%)$ and reading newspapers and books $(8.5 \%)$. Only one participant $(1.1 \%)$

Table 2: Medical information and smoking pattern of geriatric residents.

\begin{tabular}{|c|c|c|c|}
\hline \multirow{2}{*}{\multicolumn{2}{|c|}{ Medical information and smoking pattern }} & \multicolumn{2}{|c|}{ No. $=94$} \\
\hline & & \multirow{2}{*}{$\frac{F}{53}$} & \multirow{2}{*}{$\frac{(\%)}{(56.4)}$} \\
\hline Smoking pattern & Not smoker & & \\
\hline & Smoker & 31 & (33) \\
\hline & Ex-smoker & 10 & $(10.6)$ \\
\hline \multirow[t]{2}{*}{ Chronic disease } & Yes & 55 & $(58.5)$ \\
\hline & No & 39 & $(41.5)$ \\
\hline \multirow{7}{*}{$\begin{array}{l}\text { Type of chronic disease } \\
\left({ }^{*} \mathrm{No}=55\right)\end{array}$} & Diabetes mellitus & 9 & $(9.6)$ \\
\hline & Hypertension & 18 & $(19.1)$ \\
\hline & Heart disease & 6 & $(6.4)$ \\
\hline & Cardiovascular accident (CVA) & 4 & $(4.3)$ \\
\hline & Romantic arthritis & 7 & $(7.4)$ \\
\hline & Depression & 9 & $(9.6)$ \\
\hline & Asthma & 2 & $(2.1)$ \\
\hline
\end{tabular}


Daily living activities among geriatric residents ......

https://doi.org/10.15218/zjms.2017.012

was able to use a computer and religious spirituals, primarily praying $42.6 \%$ of the participants practiced (Table 3).

Table 3: Social issues and daily recreation activity information of geriatric residents.

\begin{tabular}{|c|c|c|c|}
\hline \multirow{2}{*}{ Social issues and daily recreation activity } & & \multicolumn{2}{|c|}{ No. $=94$} \\
\hline & & $F$ & (\%) \\
\hline \multirow{2}{*}{$\begin{array}{l}\text { Do you go out from geriatric home to visit } \\
\text { anyone? }\end{array}$} & Yes & 46 & $(48.9)$ \\
\hline & No & 48 & $(51.1)$ \\
\hline \multirow{4}{*}{$\begin{array}{l}\text { (If yes) Who are they? } \\
\left({ }^{*} \text { No. }=46\right)\end{array}$} & Family & 25 & $(54.3)$ \\
\hline & Relative & 11 & $(23.9)$ \\
\hline & Friends & 8 & $(17.4)$ \\
\hline & Family, Relative and Friends & 2 & $(4.3)$ \\
\hline \multirow{2}{*}{$\begin{array}{l}\text { Does anyone come to the geriatric home to } \\
\text { visit you? }\end{array}$} & Yes & 46 & $(48.9)$ \\
\hline & No & 48 & $(51.1)$ \\
\hline \multirow{3}{*}{$\begin{array}{l}\text { (If yes) Who are they? } \\
\left({ }^{*} \text { No. }=46\right)\end{array}$} & Family & 32 & $(69.6)$ \\
\hline & Relative & 13 & $(28.3)$ \\
\hline & Friends & 1 & $(2.2)$ \\
\hline \multirow[t]{2}{*}{ Do you watch television? } & Yes & 57 & $(60.6)$ \\
\hline & No & 37 & $(39.4)$ \\
\hline \multirow[t]{2}{*}{ Do you listen to the radio? } & Yes & 46 & $(48.9)$ \\
\hline & No & 48 & $(51.1)$ \\
\hline \multirow[t]{2}{*}{ Do you read the newspaper or book? } & Yes & 8 & (8.5) \\
\hline & No & 86 & $(91.5)$ \\
\hline \multirow[t]{2}{*}{ Do you use a computer? } & Yes & 1 & $(1.1)$ \\
\hline & No & 93 & $(98.9)$ \\
\hline \multirow[t]{2}{*}{ Do you do any religious spirituals? } & Yes & 40 & $(42.6)$ \\
\hline & No & 54 & $(57.4)$ \\
\hline \multirow{3}{*}{$\begin{array}{l}\text { Type of spiritual activities } \\
\left({ }^{*} \text { No. }=40\right)\end{array}$} & Pray & 40 & $(100)$ \\
\hline & Go mosque & 7 & $(17.5)$ \\
\hline & Reading religion book & 8 & (20) \\
\hline
\end{tabular}


The most common independent ADL were feeding $(92.6 \%)$, oral care $(79.8 \%)$ and toileting $(69.1 \%)$. The most common dependency ADL were shopping (43.6\%), climbing stairs $(29.8 \%)$ and bathing $(25.5 \%)$ as shown in Table 4 . More than half $(56.4 \%)$ of the participants did not have any dependent activities while $11.7 \%$ had one dependent activity, $6.4 \%$ had two dependent activities, $7.4 \%$ had three dependent activities, $6.4 \%$ had four dependent activities, and $11.7 \%$ had five or more dependent activities. The commonest dependent activities included shopping, climbing stairs, physical ambulation, bathing, and toileting (Table 5).

Table 4: Activities of daily living of geriatric residents.

\begin{tabular}{lcccccccc}
\hline & \multicolumn{2}{c}{ Independent } & \multicolumn{2}{c}{ Requires } \\
assistance & \multicolumn{2}{c}{ Dependent } & \multicolumn{2}{c}{ Total } \\
Activities of daily living & No. & $(\%)$ & No. & $(\%)$ & No. & (\%) & No. & $(\%)$ \\
\hline Feeding & 87 & $(92.6)$ & 6 & $(6.4)$ & 1 & $(1.1)$ & 94 & $(100)$ \\
Oral Care & 75 & $(79.8)$ & 15 & $(16)$ & 4 & $(4.3)$ & 94 & $(100)$ \\
Toileting & 65 & $(69.1)$ & 15 & $(16)$ & 14 & $(14.9)$ & 94 & $(100)$ \\
Bathing & 60 & $(63.8)$ & 10 & $(10.6)$ & 24 & $(25.5)$ & 94 & $(100)$ \\
Dressing & 64 & $(68.1)$ & 24 & $(25.5)$ & 6 & $(6.4)$ & 94 & $(100)$ \\
$\begin{array}{l}\text { Grooming (neatness, hair, } \\
\text { nails, hands, face, clothing) }\end{array}$ & 63 & $(67)$ & 24 & $(25.5)$ & 7 & $(7.4)$ & 94 & $(100)$ \\
Physical Ambulation & 64 & $(68.1)$ & 18 & $(19.1)$ & 12 & $(12.8)$ & 94 & $(100)$ \\
Climbing stairs & 54 & $(57.4)$ & 12 & $(12.8)$ & 28 & $(29.8)$ & 94 & $(100)$ \\
Shopping & 42 & $(44.7)$ & 11 & $(11.7)$ & 41 & $(43.6)$ & 94 & $(100)$ \\
\hline
\end{tabular}

Table 5: Distribution of participants according to the number of dependent activities.

\begin{tabular}{lcc}
\hline Number of dependent activities & No. & (\%) \\
\hline 0 & 53 & $(56.4)$ \\
1 & 11 & $(11.7)$ \\
2 & 6 & $(6.4)$ \\
3 & 7 & $(7.4)$ \\
4 & 6 & $(6.4)$ \\
$5-9$ & 11 & $(11.7)$ \\
\hline
\end{tabular}


There was a significant association between dependency of the ADL and the sex of the participants $(86.4 \%$ for females vs. $30.6 \%$ for males, $P<0.001)$, educational level $(56.1 \%$ for illiterate and can read and write, $7.1 \%$ for primary school graduates and $21.4 \%$ for secondary and higher level graduates, $P<0.001$ ) and employment status before entering the geriatric home $(50 \%$ for self-employed and $37 \%$ for retired vs. $30.8 \%$ for unemployed,
$P<0.001)$. Dependency was significantly higher in ex-smokers and non-smokers than smokers $(50 \%$ and $47.2 \%, 35.5 \%$ respectively $P<0.001)$. Dependency was significantly higher among those who were not going out from geriatric home to visit family and friends $(P<0.001)$, whom people were coming to visit them $(P=0.040)$ and who were not practicing religious spirituals $(P=0.061)$ as shown in Table 6.

Table 6: Association some of socio-demographic, medical information, social issues and daily recreation activity factors with having at least one dependent activity.

\begin{tabular}{|c|c|c|c|c|c|c|}
\hline \multirow{3}{*}{ Variable } & & \multicolumn{4}{|c|}{ Activities of daily living } & \multirow{3}{*}{$P$ value } \\
\hline & & \multicolumn{2}{|c|}{ Independent } & \multicolumn{2}{|c|}{$\begin{array}{c}\text { At least } 1 \\
\text { dependent activity }\end{array}$} & \\
\hline & & No. & $(\%)$ & No. & (\%) & \\
\hline \multirow[t]{2}{*}{ Governorate } & Erbil & 26 & $(49.1)$ & 27 & $(50.9)$ & \multirow{2}{*}{0.103} \\
\hline & Sulaymaniyah & 27 & $(65.9)$ & 14 & $(34.1)$ & \\
\hline \multirow[t]{3}{*}{ Age group (years) } & $60-70$ & 33 & $(67.3)$ & 16 & $(32.7)$ & \multirow{3}{*}{0.070} \\
\hline & $71-80$ & 12 & $(41.4)$ & 17 & $(58.6)$ & \\
\hline & $\geq 81$ & 8 & $(50)$ & 8 & $(50)$ & \\
\hline \multirow[t]{2}{*}{ Sex } & Male & 50 & $(69.4)$ & 22 & $(30.6)$ & \multirow{2}{*}{$<0.001$} \\
\hline & Female & 3 & $(13.6)$ & 19 & $(86.4)$ & \\
\hline \multirow[t]{3}{*}{ Education } & $\begin{array}{l}\text { Illiterate + can } \\
\text { read and write }\end{array}$ & 29 & $(43.9)$ & 37 & $(56.1)$ & \multirow{3}{*}{$<0.001$} \\
\hline & Primary education & 13 & $(92.9)$ & 1 & (7.1) & \\
\hline & $\begin{array}{l}\text { Secondary and } \\
\text { High graduate }\end{array}$ & 11 & $(78.6)$ & 3 & $(21.4)$ & \\
\hline \multirow{3}{*}{$\begin{array}{l}\text { Occupational status before } \\
\text { entering the geriatric home }\end{array}$} & Unemployed & 9 & $(69.2)$ & 4 & $(30.8)$ & \multirow{3}{*}{$<0.001$} \\
\hline & Retired & 17 & (63) & 10 & (37) & \\
\hline & Self-employed & 27 & $(50)$ & 27 & $(50)$ & \\
\hline \multirow{2}{*}{$\begin{array}{l}\text { Marital status before } \\
\text { entering the geriatric home }\end{array}$} & Single & 19 & $(52.8)$ & 17 & $(47.2)$ & \multirow[b]{2}{*}{0.579} \\
\hline & Married/Divorced & 34 & $(58.6)$ & 24 & $(41.4)$ & \\
\hline \multirow[t]{2}{*}{ Chronic disease } & Yes & 24 & $(53.3)$ & 21 & $(46.7)$ & \multirow{2}{*}{0.568} \\
\hline & No & 29 & $(59.2)$ & 20 & $(40.8)$ & \\
\hline \multirow[t]{3}{*}{ Smoking } & Yes & 20 & $(64.5)$ & 11 & $(35.5)$ & \multirow{3}{*}{$<0.001$} \\
\hline & No & 28 & $(52.8)$ & 25 & $(47.2)$ & \\
\hline & Ex-smoker & 5 & $(50)$ & 5 & $(50)$ & \\
\hline \multirow{2}{*}{$\begin{array}{l}\text { Do you go out from geriatric } \\
\text { home to visit anyone? }\end{array}$} & Yes & 35 & (83.3) & 9 & $(16.7)$ & \multirow{2}{*}{$<0.001$} \\
\hline & No & 18 & $(34.7)$ & 32 & $(65.3)$ & \\
\hline \multirow{2}{*}{$\begin{array}{l}\text { Does anyone come to the } \\
\text { geriatric home to visit you? }\end{array}$} & Yes & 21 & $(45.7)$ & 25 & $(54.3)$ & \multirow{2}{*}{0.040} \\
\hline & No & 32 & $(66.7)$ & 16 & $(33.3)$ & \\
\hline \multirow{2}{*}{$\begin{array}{l}\text { Do you practice any of } \\
\text { these religious spirituals? }\end{array}$} & Yes & 27 & $(67.5)$ & 13 & (32.5) & \multirow{2}{*}{0.061} \\
\hline & No & 26 & $(48.1)$ & 28 & $(51.9)$ & \\
\hline
\end{tabular}




\section{Discussion}

This study provides a general description of the residents of geriatric homes in Erbil and Sulaymaniyah in terms of socio-demographic characteristics, clinical characteristics, social and recreational activities in addition to assessing their ADL. The study revealed the main activities that are associated with high dependency rate and assessed the factors related to the dependency of ADL. This study adds to the limited available knowledge on this field in Iraqi Kurdistan context. This study might direct the policy makers and manager responsible for providing care to the geriatric persons to identify the needs of this people and direct the action toward the problems identified by this study. This study showed that independency was highest in feeding, oral care, and toileting, while dependency was highest in shopping, climbing stairs and bathing. Several other studies from different setting had similarly revealed high independency in feeding and toileting activities, ${ }^{9,10}$ and a relatively high dependency in shopping and bathing activities. ${ }^{11,12}$ However, another study from the United States of America (USA) revealed a much lower rate of dependency with bathing (12\%) and feeding (2.6\%) among the sample of elderly people in comparison to our results. ${ }^{13}$ In general, the elderly in the geriatric homes have more impairment and require more assistance to perform ADL compared with the old people living in community. ${ }^{7}$ Most study participants did not have any dependent activities. The possible reason behind this result might be attributed to the fact that most participants were in the younger age group of 60-70 years and at that age they can do most of the daily activities. The remaining participants who had dependent ADL were fairly distributed from having one dependent activity to five or more dependent activities. Normal aging changes and health problems usually lead to declines in the physical abilities of the elderly, which make them less independent, less safe and make daily tasks much harder. ${ }^{14}$ The result of our study is in agreement with another study from the USA that revealed a pretty similar proportion $(67 \%)$ of elderly being independent in all ADL. ${ }^{2}$ However, our result disagreed with another study from Spain, which showed that only $34.6 \%$ of the participants were categorized as dependent for at least one ADL. ${ }^{15}$ The results of the present study also disagreed with another study from France, where $56 \%$ of the participants were dependent in one or more ADL. ${ }^{16}$ The dependency of $A D L$ was significantly higher in females than males. This result is supported by a previous study that revealed a significant association between the sex and the elder's dependency. ${ }^{9}$ In the present study, dependency of the ADL was significantly associated with the educational level of the study participants. Another study similarly reported that education was inversely associated with the occurrence of home care. ${ }^{17}$ Our results also agreed with two other studies that revealed a significant association between educational level and the functional impairment and dependency of ADL. ${ }^{18,19}$ The dependency of ADL was significantly higher in individuals employed before entering the geriatric house than retired or unemployed. Occupational engagement among older people is viewed within occupational therapy as one of the basic premises for health. ${ }^{20}$ The result of our study partially agreed with a study from South Korean, which reported that manual workers showed a positive, significant relationship between work duration and the different measures of function. ${ }^{21}$ This study revealed that dependency of $A D L$ was significantly higher in ex-smokers and non-smokers than smokers. The result may be related to having a large number of non-smokers among the residents of the geriatric home. World Health Organization (WHO) stresses that smoking not only increases the risk of diseases such as lung cancer, but it is also negatively related to factors that may lead to important losses in 
functional capacity. Smoking can accelerate the rate of decline of bone density, muscular strength and respiratory function. $^{22}$ Our results disagree with two other studies that revealed no significant association between smoking and the functional capacity of elderly. ${ }^{23,24}$ Dependency was significantly higher among those who were not going out from geriatric home to visit family and friends, whom people were coming to visit them and who were not practicing religious spirituals. In the Islamic society, the family is the source of love, affection and reassurance and the elderly have a high position because they spend their life in growing up the children. The elderly in the geriatric homes are far away from their families and have the sense of loneliness. Engagement with family and friends is a vital issue for the life and functionality of older people. ${ }^{25}$ The results of this study agree with another study that revealed presence of significant relationship between social activities like visiting the relatives and participation in a senior citizens club or going on vacation with the number of disabilities in scale of ADL item. $^{26}$

\section{Conclusion}

The level of independency in the different ADL was relatively high, which might be attributed to having a younger age group of elderly in the geriatric homes. Dependency was significantly associated with the sex, education level, past employment status and smoking status of the participants.

\section{Conflicts of interest}

The authors report no conflicts of interest.

\section{References}

1. Sekhon H, Minhas S. A study of activities of daily living of elderly in an urban community of North India. Sch J App Med Sci 2014; 2(4):1450-4.

2. Covinsky KE, Palmer RM, Fortinsky RH, Counsell SR, Stewart AL, Kresevic D, et al. Loss of independence in activities of daily living in older adults hospitalized with medical illnesses: increased vulnerability with age. J Am Geriatr Soc 2003; 51(4):451-8.

3. Helvik A, Høgseth LD, Bergh S, Šaltytè-Benth J,
Kirkevold O, Selbæk G. A 36-month follow-up of decline in activities of daily living in individuals receiving domiciliary care. BMC Geriatr 2015; $15: 47$.

4. Pascal Iloh GU, Chuku A, Dike OJ, Amafili OP, Nnaji BC. Burden of limitations of activities of daily living among geriatric Nigerians with musculoskeletal disorders in a resource-limited Nigerian primary care clinic in Eastern Nigeria. Am J Health Res 2013; 1(1):9-16.

5. UNESCO. World education indicators. Review report, Northern Iraq; 2002. p. 11. (Accessed November 15, 2015, available at http://www.uis.unesco.org/Library/Documents/ wei02_en.pdf).

6. Seniar ME. Functional status of residents in Geriatric home in Erbil city. MSc Thesis. Hawler Medical University, College of Nursing, Erbil, Iraq; 2013.

7. Amen MR. The effectiveness of the physical rehabilitation program on psychological, nutritional status and physical functions of the elderly residents in Sulaimani geriatric home. PhD Thesis. University of Sulaimani, College of Nursing, Sulaimani, Iraq; 2012.

8. Fricke J. Activities of Daily Living. In: JH Stone, M Blouin, editors. In Encyclo Rehabil; 2010. (Accessed November 15, 2015, available at: http://cirrie.buffalo.edu/encyclopedia/en/ article/37/).

9. Gebreyohannis B, Kharel K. Needs assessment for assisted living facilities among elderly population. Thesis. Central University of Applied Sciences. Degree Program in Nursing; 2012.

10. Marouf I. Quality of life and morbidity pattern of geriatric population in Erbil city. PhD thesis. Hawler Medical University, College of Medicine: Erbil, Iraq; 2010.

11. Ahmed K. Older adults' social support and its effect on their everyday self-maintenance activities: findings from the household survey of urban Lahore-Pakistan. J S Asian Stud 2011; 26 (1):37-52.

12. Elisabeth J, Gunnar L, Palmi J, Bucht G. Functional status in elderly people after acute care and quality of life at one-year follow-up. Health Sci J 2006; 1. (Accessed November 15, 2015, available at http://www.hsj.gr/medicine/ functional-status-in-elderly-people-after-acutecare-and-quality-of-life-at-oneyear-followup.pdf).

13. Gallo JJ, Paveza GJ. Activities of daily living and instrumental activities of daily living assessment, Handbook of Geriatric Assessment. $4^{\text {th }}$ ed. MA: Jones and Bartlett Publishers; 2006. p. 193-240.

14. Fisher T. Assessing Function in the Elderly: Katz ADL and Lawton IADL. Dalhousie University. Measuring Health Outcomes; 2008. (Accessed November 15, 2015. Available at: http://clas.uiowa.edu/socialwork/files/socialwork/ Nursing HomeResource/documents/Katz\% 20ADL_LawtonIADL.pdf) 
15. Millán-Calenti JC, Tubío J, Pita-Fernández S, González-Abraldes I, Lorenzo T, FernándezArruty $\mathrm{T}$, et al. Prevalence of functional disability in activities of daily living (ADL), instrumental activities of daily living (IADL) and associated factors, as predictors of morbidity and mortality. Arch Gerontol Geriatr 2010; 50:306-10.

16. Terret C. How and why to perform a geriatric assessment in clinical practice. Ann Oncol 2008; 19(7):300-3.

17. Del Duca GF, Thumé E, Hallal PC. Prevalence and factors associated with home care among older adults. Rev Saude Publica 2011; 45(1):11320.

18. Loh KY, Khairani O, Norlaili T. The prevalence of functional impairment among elderly aged 60 years and above attending Klinik Kesihatan Batu 9 Ulu Langat, Selangor. Med J Malaysia 2005; 60 (2):188-93.

19. Donmez L, Zuhal G, Necati D. Disability and its effects on quality of life among older people living in Antalya city center. Arch Gerontol Geriatr 2005; $40(2): 213-23$.

20. Nilsson I. Occupational engagement among older people, Evaluation, Repertoire and Relation to Life satisfaction. Umeå, Sweden 2006; 1043.

21. Min J, Park JB, Lee K, Min K. The impact of occupational experience on cognitive and physical functional status among older adults in a representative sample of Korean subjects. Ann Occup Environ Med 2015; 27:11.

22. World Health Organization. Non communicable diseases and mental health cluster non communicable disease prevention and health promotion department ageing and life course. A contribution of the World Health Organization to the Second United Nations World Assembly on Ageing, Madrid, Spain. Geneva 27, Switzerland; 2002. (Accessed November 15, 2015, available at: http://www.who.int/hpr/ageing).

23. Freitas RS, Fernandes MH, Coqueiro RS, Reis Júnior WM, Rocha SV, Brito TA. Functional capacity and associated factors in the elderly: a population study. Acta Paul Enferm 2012; 25 (6):933-9.

24. Huang Y, Wueng S, Cheng C, Su K. Nutritional status of functionally dependent and non-functionally dependent elderly in Taiwan. J Am Coll Nutr 2001; 20(2):135-42.

25. Ammar W. Health system and reform in Lebanon. WHO Regional Office for the Eastern Mediterranean and Lebanese Ministry of Public Health; 2003. p. 60-75. (Accessed November 15, 2015, available at: http://www who.int/hac/crises/ IbnLenon_Health_System_and_reform_Septembe r2005.pdf).

26. Nourhashémi F, Andrieu S, Gillette-Guyonnet S, Vellas B, Albarède JL, Grandjean $\mathrm{H}$. Instrumental activities of daily living as a potential marker of frailty: A study of 7364 community-dwelling elderly women (the EPIDOS
Study). J Gerontol 2001; 56(7):448-53. 